\title{
Language and space in late modernity
}

\author{
ASTRID RAVN SKOVSE \& MIRIAN DUE STEFFENSEN
}

Our aim with this article is to explore the continuum between a traditional approach and a late modern approach to the articulation of the connection between language, place and speaker identity.

Our main question is: What meaning do listeners and speakers assign to individual language change? In order to answer this question we conducted two different studies. The first was a survey among 72 students on the island of Mors. The second study consisted of three qualitative interviews with young women who were raised on Mors and now living in Copenhagen.

The survey suggests that the connection between language and place is still very strong among language users. This connection acts in a normative way: The listeners "punish" the speakers who are believed to have changed their language by judging them negatively. The interviews suggest two different ways of articulating the language-identity-place connection. The first way reflects the traditional, romantic notion of birthplace as determining language and identity. The second way involves a late modern notion of flexible ties between place, language and identity. 